\title{
Necrosis de la raíz de la caña de azúcar (Saccharum officinarum) causada por Fusarium spp.
}

\author{
Sugarcane (Saccharum officinarum) root rot caused by Fusarium spp. \\ Patricia Martínez-Jaimes ${ }^{1}$, Edgar Martínez-Fernández ${ }^{*}$, Dagoberto Guillén-Sánchez ${ }^{2}$, \\ Ramón Suárez-Rodríguez³, José Augusto Ramírez-Trujillo³, Víctor Hernández-Velázquez ${ }^{3}$
}

${ }^{1}$ Centro de Investigaciones Biológicas, Universidad Autónoma del Estado de Morelos (UAEM), Av. Universidad 1001, Col. Chamilpa, Cuernavaca, Morelos, México, C.P. 62209.

2Escuela de Estudios Superiores de Xalostoc (UAEM), Av. Nicolás Bravo s/n, Parque Industrial Cuautla, C. P. 62717, Xalostoc, Ayala, Morelos.

${ }^{3}$ Centro de Investigación en Biotecnología (UAEM).

*Autor para correspondencia: edgar@uaem.mx

Fecha de recepción:

20 de diciembre de 2019

Fecha de aceptación:

28 de febrero de 2020

Fecha de publicación en línea:

30 de abril de 2020

Este es un artículo en acceso abierto que se distribuye de acuerdo a los términos de la licencia Creative Commons.

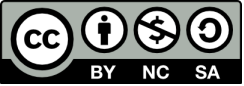

ReconocimientoNoComercial-CompartirIgual 4.0 Internacional

\section{RESUMEN}

El presente trabajo tuvo como objetivo identificar morfológica y molecularmente las especies de Fusarium causantes de la necrosis de las raíces de la caña de azúcar que inducen la sintomatología de marchitez en Morelos, México. Se llevaron a cabo colectas de plantas de caña de azúcar con síntomas de marchitez en ocho municipios de Morelos. En el laboratorio se analizaron los tejidos de los tallos y raíces mediante diferentes técnicas fitopatológicas. Se obtuvieron 65 aislamientos de Fusarium, y, con base en su morfología, se identificaron las especies F. andiyazi, F. nygamai, F. proliferatum, F. sacchari y F. verticillioides. En las pruebas de patogenicidad, las plántulas de caña de azúcar inoculadas con F. andiyazi, F. nygamai y F. sacchari mostraron el desarrollo de los síntomas de marchitez. Mediante técnicas moleculares, se confirmó la identidad de las especies de Fusarium causantes de la necrosis de las raíces de la caña de azúcar.

PALABRAS CLAVE

marchitez, caña de azúcar, Gibberella fujikuroi, estado de Morelos

\section{ABSTRACT}

The objective of this work was to identify, morphologically and molecularly, the Fusarium species that cause sugarcane root rot inducing wilt symptoms in Morelos, Mexico. Sugarcane plants were collected with wilting symptoms in eight municipalities in Morelos. In laboratory stems and roots tissues were analyzed by different phytopathological techniques. 65 Fusarium isolates were obtained, and based on their morphology, F. andiyazi, F. nygamai, F. proliferatum, F. sacchari, and F. verticillioides were identified. In the pathogenicity tests, sugarcane plants inoculated with F. andiyazi, F. nygamai, and F. sacchari developed wilting symptoms. Molecular techniques confirmed the identity of Fusarium species sugarcane root rot.

KEYWORDS

wilt, sugarcane, Gibberella fujikuroi, Morelos state 


\section{INTRODUCCIÓN}

En México, el cultivo de la caña de azúcar ocupa el cuarto lugar, sólo después del maíz, el frijol y el sorgo, y se distribuye prácticamente en todo el país. En el estado de Morelos, se reconoce una zona productora que abarca una superficie de aproximadamente 22,572 ha (SIAP 2019).

Uno de los factores limitantes en la producción de la caña de azúcar es la incidencia de enfermedades causadas por hongos, bacterias, virus y nematodos que afectan la calidad y cantidad de los productos. Como en otros cultivos, los hongos destacan por causar el mayor número de enfermedades; entre las más reconocidas, se encuentran el carbón, la roya, el pokkah boeng, la mancha café y la pudrición roja del tallo (Salgado-García et al. 2012).

En los últimos años se ha reportado una incidencia de la enfermedad de la marchitez en varias regiones cañeras del país; investigaciones efectuadas en otros países han asociado esta enfermedad con el género Pythium, que infecta las raíces (Lee y Hoy 1992; Bond et al. 2004), y con mayor frecuencia al género Fusarium, el cual afecta los tejidos de los tallos y raíces (Poongothai et al. 2014).

Las especies del género Fusarium han sido reportadas como los agentes causales de la enfermedad conocida como pokkah boeng, en caña de azúcar (Siti-Nordahliawate et al. 2008), y, más recientemente, como causante de la marchitez de estas plantas (Viswanathan et al. 2011). Los síntomas descritos consisten en clorosis, pérdida de turgencia y disminución del tamaño de las plantas.

Las especies de Fusarium asociadas con las enfermedades de la caña de azúcar pertenecen a la sección Liseola, la cual incluye especies que producen microconidios en cadenas y en falsas cabezas, pero no ocasionan clamidosporas. En otros estudios taxonómicos de Fusarium basados en sus características morfológicas, se ha reconocido un número variable dentro de esta sección: una especie (Snyder y Hansen 1945); una especie y una variedad (Booth 1971); cuatro especies y dos variedades (Nelson et al. 1981), y hasta 29 especies (Nirenberg y O'Donnell 1998).

Las técnicas moleculares han tenido un impacto significativo en la identificación de especies de hongos, así como en estudios taxonómicos y filogenéticos, incluyendo la diferenciación de grupos intraespecíficos o entre especies estrechamente relacionadas. El uso de la información de las secuencias del ADN ha revolucionado la taxonomía de Fusarium, $\mathrm{y}$, actualmente, se ha propuesto que los taxones considerados como secciones e incluso especies son, en realidad, complejos de especies integrados de varios taxones distintos. Uno de estos complejos de especies más ampliamente estudiado es Gibberella fujikuroi (Sawada) Ito in Ito \& K. Kimura, que incluye numerosas especies fitopatógenas (Hsuan et al. 2011). Este complejo de especies corresponde a los anamorfos de la sección Liseola y a otras especies originalmente clasificadas en otras secciones de Fusarium.

El presente estudio tuvo como objetivo identificar las especies de Fusarium causantes de la necrosis de las raíces de caña de azúcar en Morelos, México, usando características morfológicas y secuencias del ADN del gen que codifica para el factor de elongación de la traducción EF-1 $\alpha$.

\section{Materiales y MÉtodos}

\section{Colecta de plantas enfermas de caña de azúcar}

Se recolectaron plantas de caña de azúcar enfermas en 14 campos productores del estado de Morelos, ubicados en los municipios de Cuautla, Jojutla, Miacatlán, Tlaltizapán, Tlaquiltenango, Villa de Ayala, Xochitepec y Zacatepec (Figura 1). Las plantas con síntomas de marchitez se recogían en su totalidad si tenían un tamaño menor a un metro; en el caso de plantas de mayor tamaño, se recolectaba sólo una parte del tallo y su sistema radicular. Las plantas se colocaban en bolsas de polietileno nuevas y limpias con sus respectivos datos de colecta: localidad, fecha $\mathrm{y}$ variedad. Estas plantas se trasladaban al laboratorio de Entomología y Fitopatología del Centro de Investigaciones Biológicas de la Universidad Autónoma del Estado de Morelos (UAEM), para su análisis fitopatológico.

\section{Aislamiento de los hongos}

En el laboratorio, las raíces de las plantas colectadas se lavaron con agua corriente para eliminar las partículas de suelo y materia orgánica. De estas raíces, se eligieron fragmentos de $5 \mathrm{~mm}$ con daños de necrosis en su etapa inicial; se desinfectaron con hipoclorito de sodio a 3\% durante un tiempo de entre dos y tres minutos; posteriormente, se enjuagaron con agua destilada esterilizada, y, finalmente, se secaron con papel absorbente esterilizado. Se colocaron seis fragmentos en cada caja Petri con medio de cultivo papa dextrosa agar (PDA) acidificado $(200 \mu \mathrm{l}$ de ácido láctico a $85 \% \mathrm{~L}^{-1}$ ) y se incubaron a $24-26{ }^{\circ} \mathrm{C}$. 
Estas cajas Petri se revisaron a partir de las $24 \mathrm{~h}$ para la observación del desarrollo de hifas, a partir de los fragmentos de tejidos sembrados. Se tomó un fragmento pequeño de medio de cultivo con las hifas en desarrollo y se transfirió a una nueva caja Petri con medio de cultivo PDA. De las colonias identificadas como Fusarium, se obtuvieron cultivos monoconidiales mediante la técnica de rayado en placa (Nur-Ain-Izzati et al. 2011). De igual manera, se hicieron aislamientos de tejidos de tallos con síntomas de marchitez a diferentes niveles de los tejidos internodales.

\section{Identificación de las especies de Fusarium}

Para la identificación morfológica de los cultivos monoconidiales, se tomaron pequeños fragmentos de la periferia de las colonias y se transfirieron al centro de las cajas Petri con medio de cultivo PDA, Spezieller Nährstoffarmer Agar (SNA) y hojas de clavel agar (HCA: $20 \mathrm{~g}$ de agar en un litro de agua destilada y 12 piezas de hojas de clavel esterilizadas mediante la aplicación de rayos gamma), de acuerdo con la metodología propuesta por Leslie y Summerell (2006). A partir de los 14 días, se llevó a cabo la observación de las estructuras fructíferas de Fusarium de las colonias que crecían en los medios SNA y HCA. La identificación se basó principalmente en la observación de las dimensiones y formas de los macroconidios, microconidios, fiálides y clamidosporas; lo anterior se complementó con la observación del desarrollo de esporodoquios, así como con la determinación del color de la colonia desarrollada en PDA, siguiendo las claves y descripciones de Booth (1971), Gerlach y Nirenberg (1982) y Leslie y Summerell (2006).

\section{Pruebas de patogenicidad}

Se evaluó la patogenicidad de un aislamiento de cada una de las especies de Fusarium aisladas de los tejidos necróticos de las raíces de caña de azúcar, utilizando plántulas sanas de caña de azúcar de dos meses de edad, de las variedades CP 72 20-86 y MEX 79-431, obtenidas por cultivo in vitro. El inóculo de cada especie se obtuvo de colonias crecidas en medio PDA, con una semana de desarrollo, adicionando 10 $\mathrm{ml}$ de agua destilada estéril y raspando suavemente la superficie para obtener una suspensión de esporas. La concentración de la suspensión de inoculo fue determinada usando un hematocitómetro y ajustada a $1 \times 10^{6}$ esporas $\mathrm{mL}^{-1}$ con agua destilada estéril. Se aplicaron $30 \mathrm{~mL}$ dela suspensión deesporas en las raíces de seis plantas sanas (Chehri et al. 2010); a tres de éstas se les ocasionó una lesión con una navaja de bisturí. A las plantas testigo únicamente se les aplicaron $30 \mathrm{ml}$ de agua destilada estéril. Estas pruebas se hicieron por triplicado. En las plantas inoculadas que desarrollaron los síntomas de marchitez y crecimiento menor se procedió a analizar las raíces que presentaban necrosis para efectuar los aislamientos del agente causal. Estos aislamientos se identificaron nuevamente con base en su morfología y se comprobó su identidad mediante el análisis molecular.

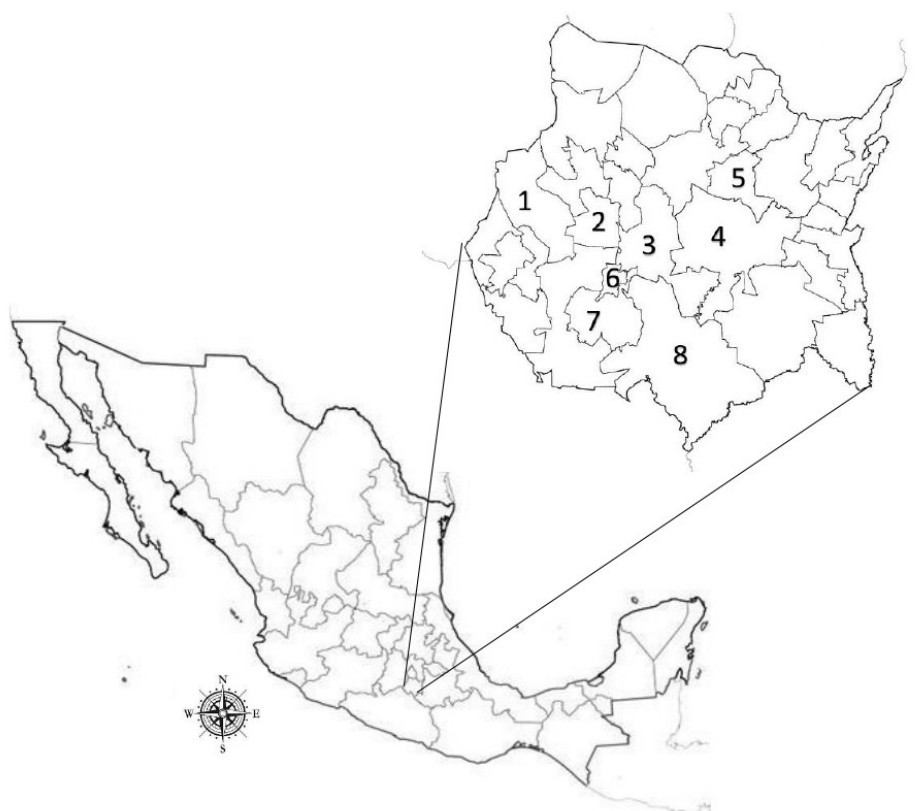

Figura 1. Municipios del estado de Morelos considerados para la colecta de plantas enfermas de caña de azúcar. 1. Miacatlán; 2. Xochitepec; 3. Tlaltizapán; 4. Villa de Ayala; 5. Cuautla; 6. Zacatepec; 7. Jojutla; 8. Tlaquiltenango. 


\section{Identificación molecular de Fusarium spp.}

Extracción de ADN. Los aislamientos monoconidiales de Fusarium se sembraron en medio PDA y se mantuvieron a una temperatura de $24-26{ }^{\circ} \mathrm{C}$ bajo luz continua. A los 12 días, el micelio se desprendió del medio de cultivo y se depositó en un tubo eppendorf de $1.5 \mathrm{ml}$. Los tubos eppendorf se colocaron en un ultracongelador durante dos horas y, posteriormente, los micelios se maceraron con una punta de teflón. Para la extracción del ADN del micelio de cada aislamiento se utilizó el estuche DNeasy ${ }^{\circledR}$ Plant Mini Kit (Qiagen, Germany), siguiendo el protocolo del fabricante. La calidad del ADN se verificó por electroforesis en gel de agarosa a $1 \%$, buffer TAE y bromuro de etidio. El ADN se visualizó en un fotodocumentador UVP MultiDoc-It.

Amplificación de los genes. El gen del factor de elongación de la traducción $1 \alpha(E F-1 \alpha)$ fue amplificado con los oligonucleótidos EF-1 (5'GTT AAG AGG CGC GGT GTC GGT GTG 3') y EF-2 (5'GGA AGT ACC AGT GAT CAT GTT3') (O'Donnell et al. 2010). Las reacciones de PCR se prepararon en un volumen final de $25 \mu \mathrm{L}$, que contenía $15.5 \mu \mathrm{L}$ de agua, $2.5 \mu \mathrm{L}$ de buffer 10X para PCR, $2 \mu \mathrm{L}$ de dNTP's $2 \mathrm{mM}, 0.75 \mu \mathrm{L}$ de $\mathrm{MgCl} 25 \mathrm{mM}, 1.5 \mu \mathrm{L}$ de cada iniciador $10 \mathrm{pmol} / \mu \mathrm{l}, 1.0$ $\mathrm{U}$ de taq-DNA polimerasa (Fermentas, Lithunia) y 1.0 $\mu \mathrm{L}$ de $\mathrm{ADN}$ fúngico. La reacción de $\mathrm{PCR}$ se efectuó en un termociclador Corbett con el siguiente programa: desnaturalización inicial a $95{ }^{\circ} \mathrm{C}$ durante 5 minutos; 37 ciclos de desnaturalización a $95{ }^{\circ} \mathrm{C}$ durante 45 segundos; alineamiento a $57^{\circ} \mathrm{C}$ durante 50 segundos; extensión a $72{ }^{\circ} \mathrm{C}$ durante un minuto, y un ciclo final de extensión a $72{ }^{\circ} \mathrm{C}$ durante 5 minutos. El producto de PCR se analizó por electroforesis en gel de agarosa (1\%) y bromuro de etidio. El producto amplificado se visualizó en un fotodocumentador UVP MultiDoc-It. Los fragmentos amplificados se purificaron mediante el Kit QIAquick PCR Purification (Qiagen, Germany), siguiendo el protocolo de la compañía. El ADN se verifico por electroforesis en gel de agarosa a 1\% y se cuantificó la muestra de ácidos nucleicos con el espectrofotómetro Nanodrop 2000 (ThermoScientific, USA).

Los fragmentos de ADN purificados fueron enviados a secuenciar a la Unidad de Síntesis y Secuenciación de ADN del Instituto de Biotecnología de la Universidad Nacional Autónoma de México (UNAM). Las secuencias de ADN fúngico obtenidas se compararon con las secuencias de la base de datos de GenBank del NCBI (National Center for Biotechnology Information), mediante el programa BLAST (Basical Alignment Search Tool).
Las secuencias fueron alineadas con el programa Clustal W (Thompson et al. 1994). El análisis filogenético se llevó a cabo con el método Neighbor-Joining, utilizando el programa MEGA 6 (Tamura et al. 2013). El árbol filogenético fue construido con el modelo Jukes-Cantor y la fiabilidad de los árboles se estimó mediante un análisis bootstrap, con 1000 repeticiones. Como grupo externo se utilizó la accesión HE647946.1 de F. solani.

\section{RESUltados Y DISCUSIÓN}

La necrosis de las raíces de la caña de azúcar se encuentra entre las enfermedades de mayor importancia económica en México (Salgado-García et al. 2012). Se ha reportado como causante de esta enfermedad a Pythium arrhenomanes (Lee y Hoy 1992), con una reducción en el crecimiento, pero sin ocasionar un estado de marchitez, como se observa en las plantas con las raíces necróticas de plantas de caña del estado de Morelos. Más recientemente, esta enfermedad ha sido reportada en 34 países productores de caña de azúcar, y se ha señalado a $F$. sacchari como el agente causal (Viswanathan 2013).

En las plantas de caña con síntomas de marchitez del estado de Morelos, se obtuvieron 65 aislamientos de Fusarium solamente de las raíces necróticas y no se consiguió el aislamiento de Fusarium de los tejidos del tallo, tal como lo han indicado Viswanathan et al. (2011), en plantas de caña de la India con la misma sintomatología.

Los aislamientos de Fusarium obtenidos de las raíces necróticas de la caña de azúcar mostraron un micelio flocoso, de blanco a púrpura, creciendo en medio del cultivo PDA. La morfología de los microconidios de todos los aislamientos fue de forma oval con la base aplanada y formados en cadena o en falsas cabezas. Las cadenas de los microconidios fueron cortas (menos de 10 microconidios), medias (de 10 a 20 microconidios) y largas (más de 20 microconidios). Basados en sus características morfológicas, estos aislamientos fueron identificados como F. andiyazi, F. nygamai, F. proliferatum, F. sacchari y F. verticillioides. Estas especies se incluyen dentro de la sección Liseola; también se ha denominado como el complejo Gibberella fujikuroi (CGF) (Nirenberg y O'Donnell 1998).

Algunos autores indican que ciertas especies de Fusarium son difíciles de distinguir tomando como base sus características morfológicas. Aunque este problema se acentúa más en el CGF, siguiendo los protocolos para la identificación morfológica (Gerlach y Nirenberg 1982; Nirenberg y O’Donnell 1998; 
Leslie y Summerell 2006) es posible observar algunas características distintivas para cada especie. De las especies identificadas en este trabajo, F. sacchari se distingue por sus microconidios ovales producidos en monofiálides $\mathrm{o}$, en ocasiones, sobre polifiálides dispuestos en grupo, formando falsas cabezas. Una especie muy parecida es $F$. nygamai, la cual presenta microconidios en cadenas cortas o en falsas cabezas, pero forman clamidosporas a las 2 o 4 semanas o hasta las 6 semanas en las hifas aéreas (Burgess y Trimboli 1986). Fusarium andiyazi, F. proliferatum y F. verticillioides producen sus microconidios en cadenas. $F$. andiyazi se distingue porque es de las pocas especies dentro del CGF que producen seudoclamidosporas. Estas estructuras son de forma casi redonda, de 7-16 $\mu \mathrm{m}$ de diámetro, terminales o intercalares, hialinas, de pared lisa, la mayoría solitarias o formando cadenas cortas (Marasas et al. 2001). Por otra parte, F. verticillioides presenta monofiálides y los conidios integran cadenas largas, mientras que F. proliferatum presenta polifiálides y los conidios están dispuestos en cadenas cortas.

Las plantas de caña de las variedades CP 72 20-86 y MEX 79-431 inoculadas en las raíces con los aislamientos 16 de $F$. andiyazi, 31 de $F$. nygamai y 51 de F. Sacchari, de manera individual presentaron paulatinamente el desarrollo de los síntomas de marchitez a partir de los 30 días y se observó una marcada reducción en el tamaño en comparación con las plantas testigo. Las raíces de estas plantas inoculadas mostraban inicialmente una coloración ligeramente café, y, posteriormente, cambiaron a un color oscuro, indicando la necrosis de estos tejidos (Figuras 2-4). Esto difiere con otros autores (Viswanathan et al. 2011; Viswanathan 2013), que han señalado que la marchitez de la caña de azúcar ocurre por la infección de F. sacchari en los tallos de estas plantas. En las plantas inoculadas con aislamientos de F. proliferatum y F. verticillioides no se observó el desarrollo de los síntomas de la marchitez y no ocurrió la necrosis de las raíces en el periodo de observación señalado.

En el presente estudio, es evidente la incidencia de especies de Fusarium de la sección Liseola en las raíces de la caña de azúcar en Morelos. De igual manera, en otras plantas gramíneas cultivadas también se han aislado e identificado especies de la sección Liseola en raíces de maíz (Chehri et al. 2010; Nur-Ain-Izzati et al. 2011), sorgo (Leslie et al. 1990), arroz (Sunder 1998) y caña de azúcar (Leslie et al. 2005). También en plantas gramíneas silvestres se ha determinado la presencia de especies de Fusarium de la sección Liseola (Nur-Ain-Izzati et al. 2009).
Actualmente, de acuerdo con algunos autores, las especies de la sección Liseola se consideran dentro del CGF (Nirenberg y O'Donell 1998). En este grupo se incluyen especies que comparten características morfológicas y biológicas, estableciendo relaciones estrechas con la distribución de sus plantas hospederas (Kvas et al. 2009).

Las especies más dominantes en las raíces necróticas de la caña de azúcar del estado de Morelos fueron F. sacchari y F. nygamai. Fusarium sacchari ha sido reportada en caña de azúcar en Asia como causante de la enfermedad conocida como Pokkah boeng (Siti-Nordahliawate et al. 2008), y en la India como agente causal de la marchitez (Viswanathan et al. 2011). También ha sido aislado de las raíces de algunas hierbas silvestres que crecen en los terrenos de estos cultivos, tales como Eleusine indica y Dactyloctenium aeygyptium, por lo que estas pantas son consideradas como sus hospedantes secundarios (Nur-Ain-Izzati et al. 2009). Por otra parte, $F$. nygamai se ha aislado de mazorcas con daños de pudrición (Nur-Ain-Izzati et al. 2011) y de plantas enfermas, tales como maíz, mango, chile, guayaba, plátano, frijol (Sapumohotti 2004) y arroz (Balmas et al. 2000). Es de amplia distribución en áreas secas y cálidas, como la región central de Australia (Sangalang et al. 1995), y se ha encontrado en regiones tropicales y húmedas, como en la península de Malasia y el archipiélago Indonesio (Salleh y Strange 1988). Fusarium andiyazi es una especie descrita por Marasas et al. (2001) a partir de aislamientos de Fusarium causantes de la pudrición de tallos y granos de sorgo de Etiopia, África del Sur y Estados Unidos. Se ha comprobado su participación como causante de la enfermedad llamada bakanae en cultivos de arroz en Italia (Dal Prá et al. 2010) y Malasia (Hsuan et al. 2011).

De los aislamientos de Fusarium causantes de la necrosis de la caña de azúcar sometidos al análisis molecular por PCR con los marcadores EF-1 y EF-2 se obtuvieron fragmentos de aproximadamente $700 \mathrm{pb}$. Las secuencias correspondientes a estos fragmentos se compararon en la base de datos FUSARIUM_ID y en NCBI, utilizando el programa BLAST. Los aislados 7, 16 y 18 mostraron una identidad de $98.3 \%$, 98.9\% y $99.3 \%$, respectivamente, con $F$. andiyazi, mientras que los aislados 31 y 51 mostraron una identidad de $99.7 \%$ con F. nygamai y $99.5 \%$ con $F$. sacchari, respectivamente. El análisis filogenético usando MEGA 6 (Tamura et al. 2013) generó un árbol de Neighbor-Joining con un total de $567 \mathrm{nt}$ analizados, excluyendo inserciones o deleciones (Figura 5). El clado I comprende a F. sacchari. El clado II corresponde a F. andiyazi. El clado III incluye a F. nygamai. 


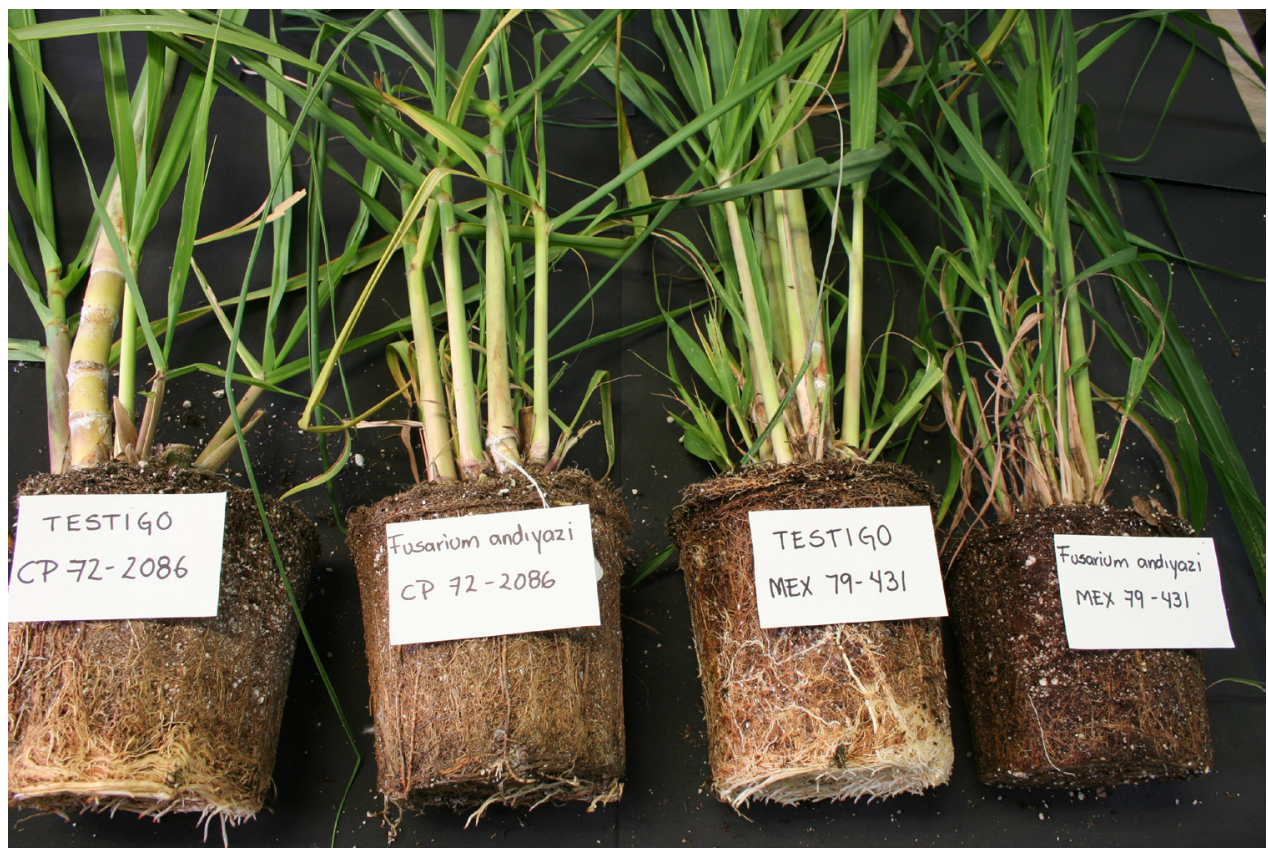

Figura 2. Raíces de las plantas de caña de azúcar inoculadas con F. andiyazi comparadas con las plantas testigo sin inocular.

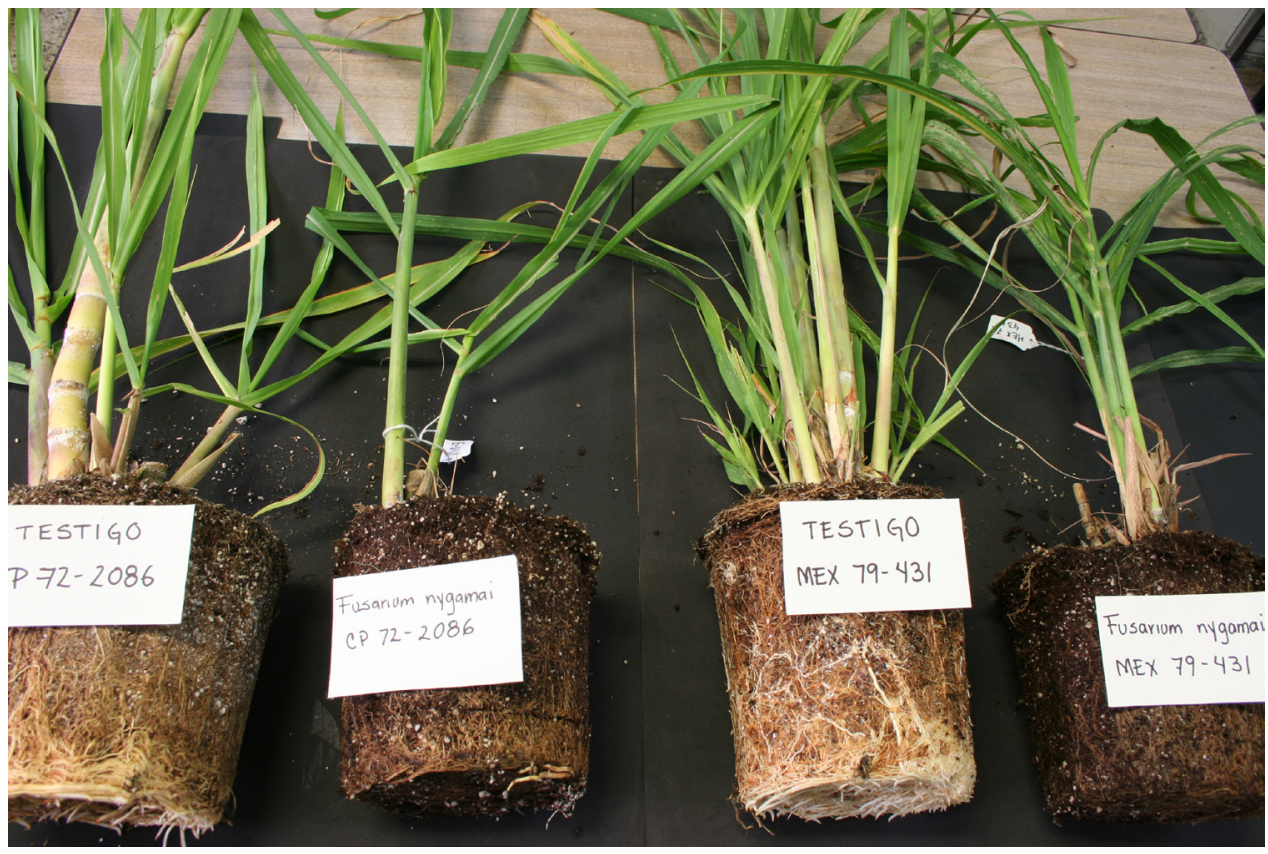

Figura 3. Raíces de las plantas de caña de azúcar inoculadas con F. nygamai comparadas con las plantas testigo sin inocular.

Recientemente, basados en la filogenia de las especies del CGF, se ha propuesto la integración de tres clados, formulando una hipótesis biogeográfica basado en los orígenes de las plantas hospedantes. De esta manera, F. nygamai junto con $F$. verticillioides se han ubicado dentro del Clado Africano, y F. sacchari se ha colocado dentro del Clado Asiático (Kvas et al. 2009), mientras que para $F$. andiyazi y otras especies no se ha establecido afinidad hacia algún grupo. 


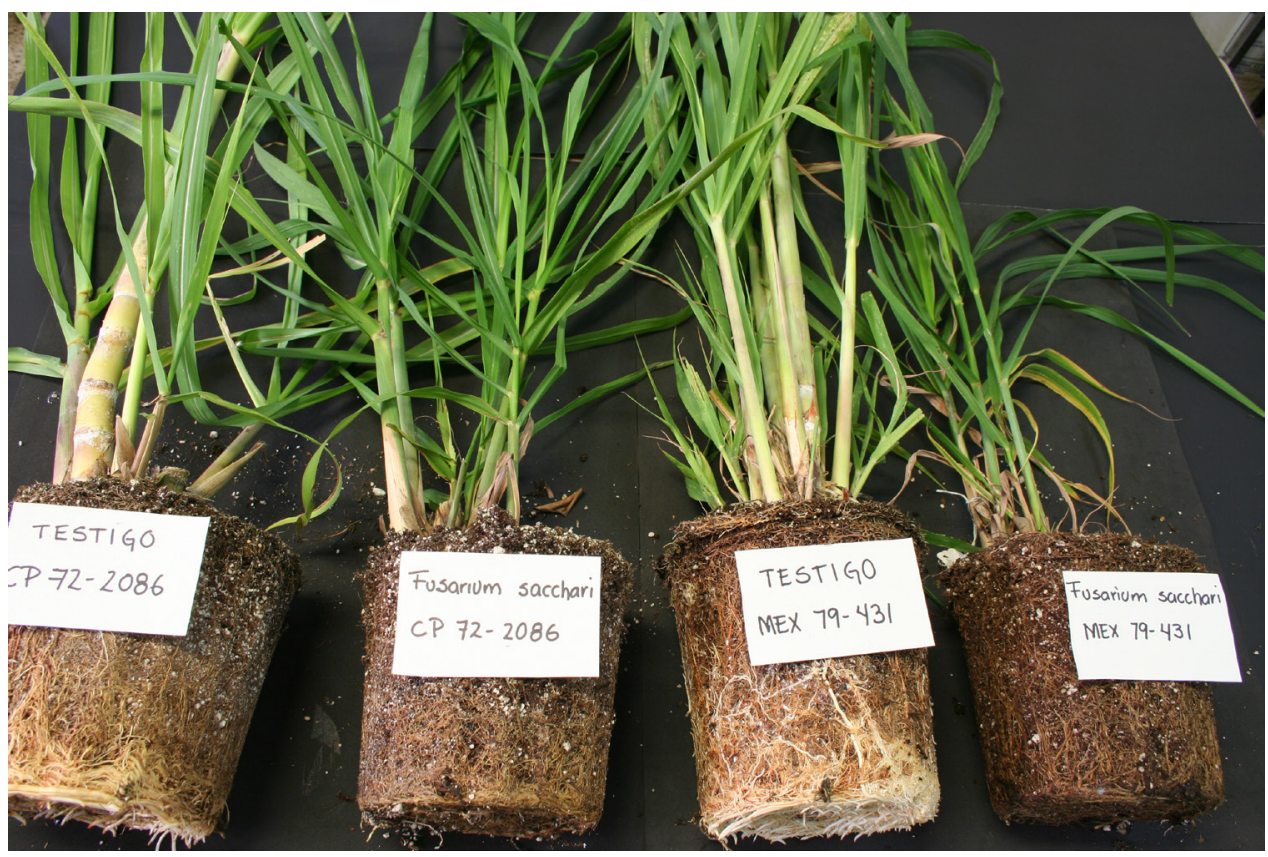

Figura 4. Raíces de las plantas de caña de azúcar inoculadas con F. sacchari comparadas con las plantas testigo sin inocular.

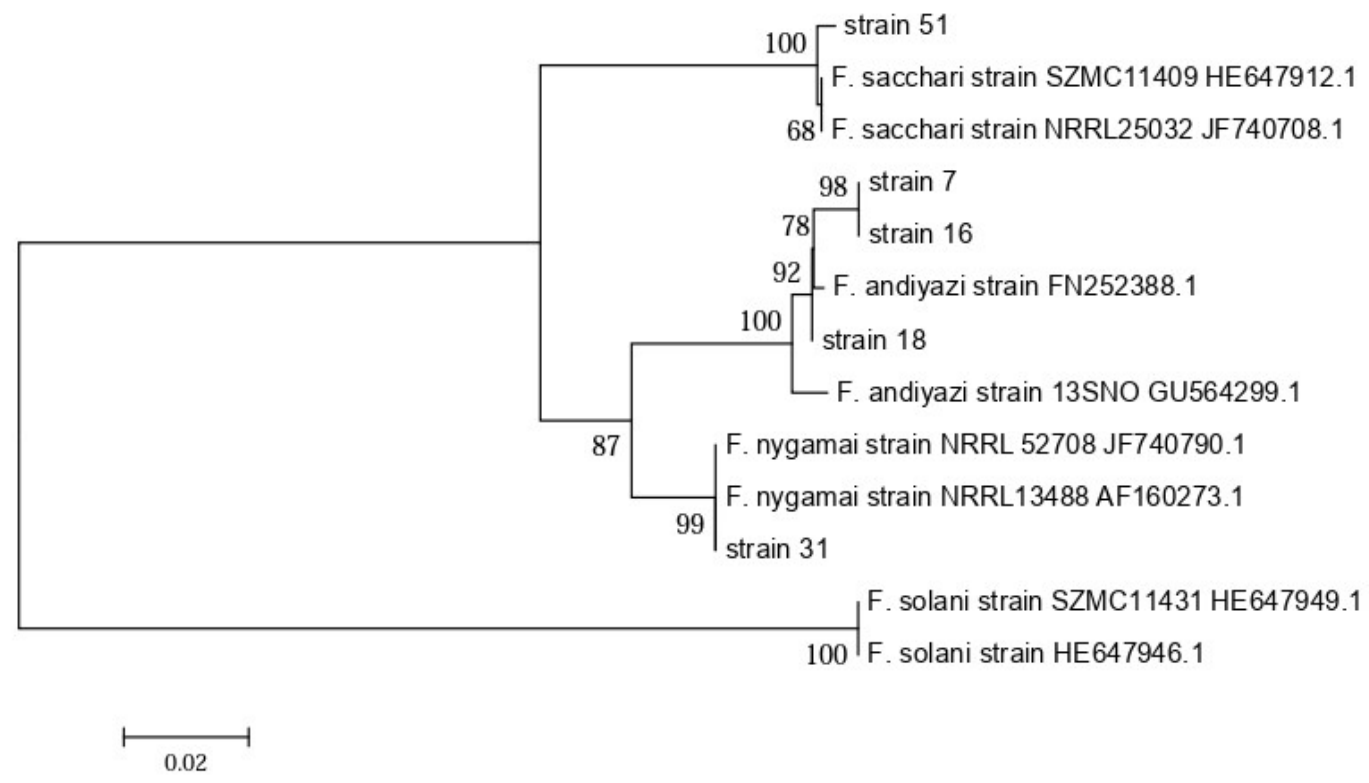

Figura 5. Árbol filogenético Neighbor-Joining basado en las secuencias del gen TEF-1 $\alpha$ de las especies de Fusarium causantes de la necrosis de las raíces de caña de azúcar. Los valores bootstrap basados en 1000 réplicas son indicados como porcentajes en los internodos cuando las frecuencias de las réplicas exceden $50 \%$.

\section{Conclusiones}

De las raíces necróticas de plantas de caña de azúcar del estado de Morelos se aislaron cinco especies del género Fusarium: F. andiyazi, F. nygamai, F. proliferatum, F. sacchari y F. verticillioides.
Mediante las pruebas de patogenicidad en plantas de caña de azúcar, se confirmó que sólo las especies F. andiyazi, F. nygamai y F. sacchari causan la necrosis de la raíz e inducen la sintomatología de marchitez en estas plantas. 


\section{LiTERATURA CITADA}

Balmas V, Corda P, Marcello A, Bottalico A. 2000. Fusarium nygamai associated with Fusarium foot rot of rice in Sardinia. Plant Disease 84(7): 807. https://doi. org/10.1094/PDIS.2000.84.7.807B

Bond JP, McGawley EC, Hoy JW. 2004. Sugarcane growth as influenced by nematodes and Pythium arrhenomanes. Nematropica 34: 245-256.

Booth C. 1971. The Genus Fusarium. Commonwealth Mycological Institute. Kew, Surrey, United Kingdom.

Burgess LW, Trimboli D. 1986. Characterization and distribution of Fusarium nygamai, sp. nov. Mycologia 78(2): 223-229. https://doi.org/10.2307/3793167

Chehri K, Zafari D, Nurhazrati M, Salleh B, Reddy KRN, Karami E. 2010. Natural occurrence of Fusarium species associated with root and stalk rot of maize in Kermanshah Province, Iran. Journal of Biological Sciences 10(8): 795-799. https://doi.org/10.3923/jbs.2010.795.799

Dal Prá M, Tonyi S, Pancaldi D, Nipoti P, Alberti I. 2010. First report of Fusarium andiyazi associated with rice bakanae. Plant Disease 94(8): 1070. https://doi. org/10.1094/PDIS-94-8-1070A

Gerlach W, Nirenberg H. 1982. The genus Fusarium-a Pictorial Atlas. Biologische Bundesanstalt für Land-und Forstwirtschaft Institut für Mikrobiologie. Berlin.

Hsuan HM, Salleh B, Zakaria L. 2011. Molecular identification of Fusarium species in Gibberella fujikuroi species complex from rice, sugarcane and maize from Peninsular Malaysia. International Journal of Molecular Sciences 12: 6722-6732. https://doi.org/10.3390/ijms12106722

Kvas M, Marasas WFO, Wingfield BD, Wingfield MJ, Steenkamp ET. 2009. Diversity and evolution of Fusarium species in the Gibberella fujikuroi complex. Fungal Diversity 34: 1-21.

Lee YS, Hoy JW. 1992. Interactions among Pythium species affecting root rot of sugarcane. Plant Disease 76: 735739. https//doi.org/10.1094/PD-76-0735

Leslie JF, Summerell BA. 2006. The Fusarium Laboratory Manual. Blackwell Publishing. Iowa, USA.

Leslie JF, Pearson CAS, Nelson PE, Toussoun TA. 1990. Fusarium spp. from corn, sorghum and soybean fields in the central and eastern United States. Phytopathology 80: 343-350. https://doi.org/10.1094/Phyto-80-343

Leslie JF, Summerell BA, Bullock S, Doe FJ. 2005. Description of Gibberella sacchari and neotypification of its anamorph Fusarium sacchari. Mycologia 97: 718-724.

Marasas WFO, Rheeder JP, Lampretch SC, Zeller KA, Leslie JF. 2001. Fusarium andiyazi sp. nov., a new species from sorghum. Mycologia 93: 1203-1210. https://doi. org/10.2307/3761681

Nelson PE, Toussoun TA, Cook RJ. 1981. Fusarium: Diseases, Biology and Taxonomy. Pennsylvania State University Press, University Park, Pennsylvania.

Nirenberg HI, O'Donnell K. 1998. New Fusarium species and combinations within the Gibberella fujikuroi species complex. Mycologia 90: 434-458. https:doi. org/10.2307/3761403
Nur-Ain-Izzati MZ, Azmi AR, Siti-Nordahliawate MS, Nor-Azlina J. 2011. Contribution of the knowledge of diversity of Fusarium associated with maize in Malaysia. Plant Protection Science 47(1): 20-24. https://doi. org/10.17221/52/2008-PPS

Nur-Ain-Izzati MZ, Siti-Nordahliawate MS, Nor-Azlina J, Salleh B. 2009. Distribution and diversity of Fusarium species associated with grasses in ten states throughout peninsular Malaysia. Biotropia 16(2): 55-64. https://doi.org/11.598/btb.2009.16.2.57

O'Donnell K, Sutton DA, Rinaldi MG, Sarver BA, Balajee SA, Schroers HJ, Summerbell R C, Robert VA, Crous PW, Zhang N, Aoki T, Jung K, Park J, Lee YH, Kang S, Park B, Geiser DM. 2010. Internet-accessible DNA sequence database for identifying fusaria from human and animal infections. Journal of Clinical Microbiology 48: 3708-3718. https://doi.org/10.1128/JCM.00989-10

Poongothai M, Viswanathan R, Malathi O, Sundar AR. 2014. Sugarcane wilt: pathogen recovery from different tissues and variation in cultural characters. Sugar Tech 16(1): 50-66.

Salgado-García S, Lagunes-Espinoza LC, Núñez-Escobar R, Ortíz-García CF, Bucio-Alanís L, Aranda-Ibáñez EM. 2012. Caña de Azúcar. Producción Sustentable. Colegio de Postgraduados, Texcoco, México.

Salleh B, Strange RN.1988. Toxigenicity of some Fusaria associated with plant and human diseases in the Malaysian Peninsula, Malaysia. Journal of General Microbiology 134: 841-848. https://doi.org/10.1099/00221287134-3-841

Sangalang AE, Backhouse D, Burgess LW. 1995. Mycogeography of Fusarium species in soils from tropical, arid and mediterraean regions of Australia. Mycological Research 99: 523-528. https://doi.org/10.1016/S09537562(09)80707-7

Sapumohotti WP. 2004. Existence of Fusarium nygamai in the southern region of Sri Lanka and a key for their characterization. Tropical Agricultural Research and Extension 7: 150-154.

[SIAP] Servicio de Información Agroalimentaria y Pesquera [internet]. 2019. Producción Agrícola. [cited 2019 Dec 10]. Disponible en: http:www.gob.mx/siap/ acciones-y-programas/producción-agrícola-33119.

Siti-Nordahliawate MS, Nur Ain Izatti MZ, A. R. Azmi, Salleh B. 2008. Distribution, morphological characterization and pathogenicity of Fusarium sacchari associated with pokkah boeng disease of sugarcane in Peninsular Malaysia. Journal of Tropical Agriculture and Food Science 31: 279-286.

Snyder WC, Hansen HN. 1945. The species concept in Fusarium with reference to discolor and other sections. American Journal of Botany 32: 657-666.

Sunder SS. 1998. Vegetative compatibility, biosynthesis of GA3 and virulence of Fusarium moniliforme isolates from bakanae disease of rice. Plant Pathology 47: 767772. https://doi.org/10.1046/j.1365-3059.1998.00303.x

Tamura K, Stecher G, Peterson D, Filipski A, Kumar S. 2013. MEGA6: Molecular evolutionary genetics analy- 
sis version 6.0. Molecular Biology and Evolution 30: 2725-2729. https://doi.org/10.1093/molbev/mst197

Thompson JD, Higgins DG, Gibson TJ. 1994. CLUSTAL $\mathrm{W}$ : improving the sensitivity of progressive multiple sequence alignment through sequence weighting, position specific gap penalties and weight matrix choice. Nucleic Acids Research 22: 4673-4680.

Viswanathan R. 2013. Status of sugarcane wilt: one hundred years after its occurrence in India. Journal of Sugarcane Research 3(2): 86-106.

Viswanathan R, Poongothai M, Malathi P. 2011. Pathogenic and molecular confirmation of Fusarium sacchari causing wilt sugarcane. Sugar Tech 13: 68-76. https:// doi.org/10.1007/s12355-011-0066-4 